\title{
Novamente esse "papinho" de humanização do cárcere?: a APAC de Pato Branco e a valorização do ser humano ${ }^{1}$
}

\section{Again this "chit chat" of humanization of jail?: Pato Branco's APAC and the valorization of the human being}

\author{
Rudy Heitor Rosas \\ Josiele Correia Guimarães Tauffer ${ }^{\star \star}$ \\ Constantino Ribeiro de Oliveira Junior ${ }^{\star \star \star}$
}

\begin{abstract}
Resumo: Este artigo é parte das pesquisas realizadas no Grupo de Estudos Contemporâneos em Execução Penal, no Centro Universitário Campo Real. O objeto de estudo é o sistema utilizado pela Associação de Proteção e Assistência aos Condenados (APAC), especificamente a APAC de Pato Branco/PR e tem como objetivo analisar a diferença de tratamento recebido pelos recuperandos dentro do sistema APAC e no sistema "tradicional" de execução penal. É uma pesquisa exploratória, de abordagem qualitativa. Foram realizadas entrevistas individuais, na modalidade fechada (exigência do campo de pesquisa) e com posterior análise de conteúdo. Participaram da pesquisa 20 (vinte) recuperandos. Da análise surgiram diversas categorias, sendo tratada no presente trabalho aquela que julgamos de maior relevância: o tratamento humanitário recebido na APAC. Isso nos permitiu concluir que o sistema APAC altera significativamente a forma como o próprio recuperando enxerga o cárcere e o tratamento entregue pelos órgãos de controle, tendo potencial de impacto na ressocialização.
\end{abstract}

Palavras-chave: APAC Pato Branco. Tratamento degradante. Humanização.

\footnotetext{
${ }^{1}$ Uma versão preliminar deste texto foi apresentada no "III SIMPÓSIO INTERNACIONAL INTERDISCIPLINAR EM CIÊNCIAS SOCIAIS APLICADAS: Democracia e direitos humanos" realizado em Ponta Grossa- PR, entre 11 a 13 de setembro de 2019 , sendo indicado pelo evento para compor este volume especial da Emancipação.

* Doutorando e Mestre em Ciências Sociais Aplicadas (UEPG), doutorando em Direito (UFPR), graduado em Direito pelo Centro Universitário Campo Real, professor de Criminologia no Centro Universitário Campo Real, advogado.

** Graduada em Direito pelo Centro Universitário Campo Real. Advogada.

*** Doutor em Educação Física pela Universidade Estadual de Campinas, mestre em Educação pela Universidade Metodista de Piracicaba, graduado em Educação Física - Licenciatura pela Universidade Estadual de Ponta Grossa (1990), professor adjunto da Universidade Estadual de Ponta Grossa, lotado no departamento de Educação Física e no Programa de PósGraduação em Ciências Sociais Aplicadas (Mestrado e Doutorado), líder do grupo de pesquisa “Lazer, Esporte e Sociedade”.
}

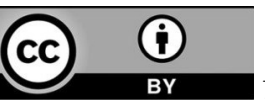




\begin{abstract}
This article is part of the research conducted at the Contemporary Studies Group on Criminal Execution at the Campo Real University Center. The object of study is the Association of Protection and Assistance to the Convicted (APAC) system, specifically the Pato Branco's/PR APAC and aims to analyze the difference of treatment received by the recovering within the APAC system and in the "traditional" system of criminal execution. It is an exploratory research with a qualitative approach. Individual interviews were conducted, in closed mode (requirement of the research field) and with subsequent content analysis. Twenty (20) recovering participated in the research. Several categories emerged from the analysis, and the one we considered to be the most relevant in the present study: the humanitarian treatment received at APAC. This allowed us to conclude that the APAC system significantly alters the way the recovering itself sees the prison and the treatment delivered by the control agencies, having potential impact on resocialization.
\end{abstract}

Keywords: APAC Pato Branco. Degrading treatment. Humanization.

\title{
Introdução
}

\author{
Ratatatá, mais um metrô vai passar. \\ Com gente de bem, apressada, católica. \\ Lendo jornal, satisfeita, hipócrita. \\ Com raiva por dentro, a caminho do Centro. \\ Olhando pra cá, curiosos, é lógico. \\ Não, não é não, não é o zoológico \\ (Racionais MC's - Diário de um detento)
}

Ao mesmo passo que a composição dos Racionais elencada acima faz todo sentido para um trabalho que pretende enfrentar a questão carcerária, ao mesmo tempo ela parece já não dar conta do ódio que oscila ao entorno da questão prisional. Pode parecer exagero - e não se aplicar de forma universal -, mas por vezes, especialmente nos meios comunicacionais de massa, tem-se a impressão de que um zoológico possui maior 'benevolência' quando o assunto é proteção do que as penitenciárias e cadeias brasileiras.

A frase "bandido bom é bandido morto" é antiga e clichê, mas isso não lhe retira a veracidade e a atualidade. As pessoas perdem completamente a identificação com o preso, que passa a ser um outro a ser combatido, um outro que pode ser sacrificado (AGAMBEM, 2002), um outro indigno de vida (ZACCONE, 2015).

Ao ser inserido nesse locus, o preso passa a ser o destinatário perfeito de toda a raiva que está dentro, ele passa a figurar como o alvo, em que será despejado o rancor social. O preso é o instrumento de catarse ${ }^{2}$.

\footnotetext{
${ }^{2}$ A catarse aparece na obra de Aristóteles como uma forma de expurgo da violência natural do ser humano através da teatralização da violência, do drama (SILVA, 1998). Segundo Queiroz (2013): “O termo catarse é de origem grega, кá $\theta \alpha \rho \sigma \varsigma$ (kátharsis), sendo usado com o sentido etimológico de purificar, purgar ou limpar. Do mesmo radical grego origina-se a palavra к $\alpha$ $\alpha \rho$ ó (katharó; em português, cátaro), que significa puro. Cátaro (katharó) é alguém que passou por uma catarse (kátharsis), isto é, um processo de purificação". Esse conceito também será explorado de forma recortada ao lazer por Elias e Dunning (1992), mas em todos os cenários a noção de catarse mantém o sentido de algo que vem de dentro para fora, como externalização.
} 
Porém, ao ser esse destinatário da ojeriza, não somente a figura do preso se torna estigmatizada e desvalorizada, mas as estruturas que compõe esse ambiente também. Não é por menos que vemos um sistema penitenciário falido, sem perspectiva de mudanças basilares e que, há muito, já parece não ser mais do que um espaço para depósito de pessoas (WACQUANT, 2011).

É por conta dessas constatações, que perpassam uma parte significativa da leitura especializada em execução da pena e em criminologia, que essa pesquisa começou a ser desenvolvida. O incômodo com o modelo atual de gestão prisional levou, durante as investigações, ao conhecimento da Associação de Proteção e Assistência aos Condenados (APAC).

Quando foi possível perceber que a APAC era de fato um modelo completamente diferente de gestão prisional (conforme se demonstrará na sequência) e que os recuperandos ${ }^{3}$ que estão nas APACs já passaram pelo sistema tradicional ${ }^{4}$, surgiu a possibilidade de confrontar os modelos e, dessa dialética, extrair informações válidas e com maior proximidade da realidade.

Dessa forma emergiu o problema de pesquisa que orientou o processo de pesquisa: a APAC é um modelo que se aproxima mais do ideal de ressocialização e humanização do tratamento dado ao apenado?

Por ser um problema de pesquisa que não comporta recorte temporal, já que a metodologia eleita pretende trabalhar com uma realidade percebida dentro de um momento específico, sem confrontações históricas, frisa-se que não foi possível inicialmente inserir um recorte temporal no problema de pesquisa, mas aponta-se que a pesquisa de campo foi realizada em 2018. No que concerne aos recortes de local e temática, o local de pesquisa eleito foi a APAC de Pato Branco (a escolha está explicada no item 3 deste artigo). Sobre o recorte temático ele já está contemplado no problema exposto, comportando dois núcleos que merecem maiores explicações.

Sobre ideal de ressocialização apontamos para dois pontos. O primeiro deles é a escolha do termo 'ressocialização'. Há uma discussão ainda não finalizada pela literatura sobre o uso desse termo, alguns optam pela 'reintegração social's, outros pela ressocialização. Fazemos a opção por 'ressocialização' por ser utilizado na Exposição de Motivos da Lei de Execução Penal (1983) e pela vertente jurídica que perpassa esse trabalho, área que privilegia durante a formação acadêmica a terminologia empregada aqui. O segundo ponto que relaciona-se com o ideal. Desde 1984 a Lei de Execução Penal (LEP), traz em seu artigo 1ํo que "A execução penal tem por objetivo efetivar as disposições de sentença ou decisão criminal e proporcionar condições para a harmônica integração social do condenado e do internado" (1984, grifo nosso), em outras palavras, ressocialização (ou reintegração social), porém, conforme os últimos números apontados pelo Departamento Penitenciário Nacional (DEPEN), a população carcerária só faz crescer, em ritmo completamente desproporcional ao crescimento da população em geral (INFOPEN, 2019) ${ }^{6}$,

\footnotetext{
${ }^{3}$ Desse ponto em diante será evitado ao máximo o uso de termo diverso a 'recuperando' - assim como já foi no resumo - porque os reclusos no sistema APAC não são chamados pelos nomes típicos utilizados no sistema tradicional. Em nosso entendimento, essa opção é extremamente coerente, pois se os discursos constituem uma realidade normatizada (FOUCAULT, 2014), então o policiamento linguístico é sempre exigível dos pesquisadores.

${ }^{4}$ Damos o nome de 'sistema tradicional' ao cárcere que conhecemos e que está previsto na Lei de Execução Penal, mais especificamente os presídios, cadeias públicas e casas de custódia (CDC).

${ }^{5}$ Para uma leitura sobre essa discussão, ainda que em nível socioeducação, vale a leitura do texto Reintegração social ou ressocialização: a visão utilitária da educação para jovens e adultos em situação de privação de liberdade. (SANT'ANNA, 2014), e ainda num texto do IPEA (2015), intitulado o desafio da reintegração social do preso: uma pesquisa em estabelecimentos prisionais.
}

${ }^{6}$ Alguns dados e referenciais que suportam a pesquisa foram atualizados para a publicação de artigo. 
demonstrando que o sistema tradicional de encarceramento (amplamente utilizado em todos os estados e Distrito Federal) não tem reduzido a violência, muito pelo contrário.?

O segundo núcleo é a humanização. Pelo menos desde 2015, quando o Supremo Tribunal Federal se debruçou sobre a Ação de Descumprimento de Preceito Fundamental (ADPF) 347 e considerou que o Sistema Prisional Brasileiro se enquadra como "Estado de Coisas Inconstitucional", por conta da sistemática violação dos direitos humanos ${ }^{8}$, falar em humanização é afirmar que os Direitos Fundamentais estampados na Constituição Federal e os demais Tratados Internacionais que defendem os Direitos Humanos devem ser observados, por isso a análise no item 4 foca tanto na questão humanitária, por ser algo necessário dentro de uma sociedade que se diz democrática e que afirma seguir uma Constituição como documento civilizatório.

As escolhas feitas por nós em 2018, quando da construção do problema de pesquisa, especialmente os núcleos 'ressocialização' e 'humanização' acabaram sendo reforçadas pela visita do Ministro da Justiça à APAC de Santa Luzia/MG, realizada em 2019, quando o DEPEN reconhece que os fundamentos que orientam as APACs são a "ressocialização e humanização da pena" (DEPEN, 2019).

Com o problema de pesquisa mais bem delimitado, foi desenvolvido projeto de pesquisa e encaminhado para avaliação ética (Registrado sob o CAAE-Certificado de Apresentação para Apreciação Ética nº 81114617.0.0000.0106), sendo aprovado em 26 de fevereiro de 2018, pelo Comitê de Ética em Pesquisa da Universidade Estadual do Centro-Oeste do Paraná (COMEP-UNICENTRO), através do Parecer Consubstanciado nº 2.513.623.

Da pesquisa principal, um dos objetivos mais fundamentais era confrontar o tratamento, dito degradante, do sistema tradicional em relação ao modelo APAC. Como objetivos secundários tivemos a exploração do modelo APAC, especialmente a sua construção histórica, bem como a sua forma de abordar a execução da pena por um caminho diverso. Outro objetivo foi o mapeamento das perspectivas criminológicas aplicáveis à pesquisa. Estes objetivos específicos estão apresentados no item seguinte, dentro do tópico "Marco-teórico".

A confrontação entre o que optamos por chamar de sistema tradicional de punição e o modelo APAC é que perpassa todo o corpo do trabalho que ora se apresenta.

\section{Marco-teórico}

Dividimos o referencial teórico em dois momentos, pois um se destina às explicações do que consiste a APAC, e outro mais 'acadêmico' que forma a base criminológica em que se assenta a análise. Também devemos reconhecer que, ainda que sejam apontados alguns autores principais, esse trabalho é perpassado pela obra e as teorias de outros vários pesquisadores e pesquisadoras, sendo impraticável apontar um só recorte epistêmico.

Um dos principais referenciais sobre APAC é Mario Ottoboni $(2001,2004,2006)$ e a Fraternidade Brasileira de Assistência aos Condenados - FBAC. Em geral as pesquisas e escritos que envolvem as APACs, partem desses dois referenciais (SÁ, 2012; MUHLE, 2013; MIRANDA, 2015; GONÇALVES; ROCHA, 2017; PIMENTA; FONSECA, 2018).

\footnotetext{
${ }^{7}$ Não se apresenta o número de ressocializados ou de reincidentes no Brasil, ou mesmo em nível estadual, porque não há dados seguros (cientificamente comprováveis) sobre esse quantitativo.

${ }^{8}$ Análise bastante interessante e esclarecedora sobre a ADPF 347 e os seus impactos na realidade a partir dos poderes constituídos pode ser lida em Magalhães (2019).
} 
As APACs, de forma sintética, surgem em 1972, com um grupo de 15 (quinze) voluntários católicos do Movimento de Cursilhos de Cristandade (MCC) (CAMPOS, 2017). Nesta época havia outro significado para a APAC, qual seja: “Amando o Próximo Amarás a Cristo”, com o lema: “estive preso e me visitastes” (TJMG, 2011). É através de Mário Ottoboni, em conjunto com a Pastoral Carcerária, que as APACs vão se aproximando da execução da pena e dos caminhos formais a ela vinculados.

Conforme Ottoboni e Ferreira (2004, p. 65):

[...] tudo era empírico e objetivava tão-somente resolver o problema da comarca, cuja população vivia sobressaltada com as constantes fugas, rebeliões e violências verificadas naquele estabelecimento prisional. o grupo não tinha parâmetros nem modelos a serem seguidos. Muito menos experiências com o mundo do crime, das drogas e das prisões. Mesmo assim, pacientemente, foram sendo vencidas as barreiras que surgiram no caminho.

Em 1974 (decorridos apenas 02 (dois) anos da gênese do método) nascia a primeira APAC, uma entidade civil de direito privado, sem fins lucrativos, com personalidade jurídica própria. (D’AGOSTINI; RECKZIEGEL, 2016). Em 1986, a APAC Itaúna-MG, torna-se referência de alcance mundial pelo reconhecimento das Nações Unidas (TJMG, 2009).

No Brasil, de acordo com a (FBAC, 2016), os seguintes Estados possuem APACs implantadas em seus territórios ou em processo de implantação: Distrito Federal (DF), em 1 (uma) cidade estando em processo de implantação; Espírito Santo (ES), em 3 (três) cidades, sendo 2 (duas) em processo de implantação; Maranhão (MA), em 8 (oito) cidades, todas implantadas; Minas Gerais (MG), em 72 (setenta e duas) cidades, tendo 39 (trinta e nove) implantadas; Mato Grosso (MT), em 1 (uma) cidade em processo de implantação; Paraná (PR), em 18 (dezoito) cidades, tendo 2 (duas) implantadas; Rio Grande do Norte (RN), em 1(uma) cidade, já implantada; Rio Grande do Sul (RS), em 02 (duas) cidades, em processo de implantação; Rondônia (RO), em 3 (três) cidades, em processo de implantação e Santa Catarina (SC), em 1 (uma) cidade, já implantada. Totalizando, aproximadamente, 110 projetos implantados ou em processo de implantação.

No Estado do Paraná, a primeira APAC foi implantada em setembro de 2012 na cidade de Barracão e, após, foi implantada a APAC em Pato Branco (FBAC, 2016).

Ottoboni (2001, p. 20) explica o propósito do método APAC:

Porque o método? Porque se trata de uma metodologia que rompe com o sistema penal vigente, cruel em todos os aspectos e que não cumpre a finalidade da pena: prepara o condenado para ser devolvido em condições de conviver harmonicamente e pacificamente com a sociedade. 0 método cuida em primeiro lugar da valorização humana da pessoa que errou e que, segrega ou não, cumpre pena privativa de liberdade.

O Conselho Nacional de Justiça (2017) descreve a APAC como:

[...] um estabelecimento de ressocialização de presos que cumprem pena, autorizados pelo juiz de execução penal da região. Lá, o condenado encontra uma rotina de trabalho e educação, diferente do ócio obrigatório vivido atrás das grades dos presídios comuns. Um quadro fixo de funcionários e grupos de voluntários asseguram um rol de atividades variadas com o objetivo de preparar o preso para voltar ao convívio em sociedade, desde terapia à religião. Para aumentar as chances de sucesso no retorno à sociedade, as visitas de familiares 
facilitam o contato entre presos e visitantes - mães, companheiras e filhos de presos, sobretudo - sem expor a segurança da casa.

Assim, conforme se depreende das citações retro, a APAC visa garantir que a execução da pena se dê de forma diversa ao "sistema penal vigente" que é "cruel em todos os aspectos" (OTTOBONI, 2001, p. 20). Ela tenta aproximar não somente os recuperandos do pessoal que presta serviço nas APACs, mas também de seus familiares e da própria comunidade, pois isso se coaduna com os objetivos apaquianos: "I - Recuperar o preso; II - Proteger a sociedade; III - Socorrer a vítima; e IV - Promover a Justiça” (DEPEN, 2019, p. 7).

Para implementar sua metodologia, as APACs orientam-se por 12 princípios/pilares: 1. Participação da Comunidade; 2. Recuperando ajudando Recuperando; 3. Trabalho; 4. Espiritualidade; 5. Assistência jurídica; 6. Assistência à saúde; 7. Família; 8 . O Voluntário e o curso para sua formação; 9. Centro de Reintegração Social - CRS; 10. Mérito; 11. Jornada de Libertação; 12. Valorização Humana.

Cada um desses doze elementos tem suas particularidades, mas para os fins desse artigo, nossa análise foca no item 12, pelos motivos já elencados na introdução e também porque, em nossa interpretação, todos os outros onze pilares auxiliam na valorização humana

Com esse cenário apresentado, acreditamos ser possível, ainda que até aqui somente em nível teórico, afirmar que a APAC surge como uma forma de combater, ou ao menos alterar, o panorama que se formou na temática carcerária.

Naquilo que tangencia a Criminologia, iniciamos a análise por David Garland e Loïc Wacquant. Para Garland (2008) as políticas de encarceramento adotadas são uma forma de vingança. Visando a satisfação da sociedade, nascem as chamadas medidas populistas, deixando de lado a dignidade do ser humano. Neste mesmo contexto, Wacquant (2002) entende que houve um deslocamento que converteu o estado de bem-estar em estado penal, pois, segundo ele, a ascensão do neoliberalismo trouxe uma descrença generalizada no modelo de welfare state, tendo como efeito na seara criminal (pena e cárcere) a descrença na ressocialização?.

Para melhor compreendermos a postura desses dois autores, precisamos compreender algumas categorias teóricas específicas.

Há necessidade de se demonstrar o link entre Bem-estar Social, individualismo e tratamento desprendido ao crime para elucidarmos a o que de fato queremos afirmar com "estado penal".

Não é fácil categorizar o Brasil dentro dos estudos de bem-estar social pois: a) uma quantidade significativa de teóricos precursores são de origem europeia ocidental, ou seja, estão

\footnotetext{
${ }^{9}$ Um artigo extremamente valioso para iniciar as leituras criminológicas sobre a crítica à ressocialização pode ser encontrado em TOZI, Thalita A. Sanção. A (re)interpretação do papel da progressão de regime de cumprimento de pena à luz do pensamento de Alessandro Baratta. Revista Liberdade, São Paulo, ed. 20, p. 85-106, set./dez. 2015, mas em síntese, quando abordamos a falência na ressocialização queremos dizer o seguinte. Dentro das finalidades da pena se fala em retribuição, que é o ato de 'devolver' a dor causada pelo ofensor, através da pena, de forma proporcional ao delito cometido e às condições de cometimento. Ainda se tem como finalidade da pena a prevenção, que se subdivide em quatro, duas chamadas gerais, que miram a sociedade como destinatária da pena e duas especiais, que focam, em tese, no indivíduo: a) prevenção geral positiva, que seria a crença no sistema legal e nas instituições, quando o Direito funciona punindo um ofensor; b) prevenção geral negativa, que é o medo que a punição pode gerar na população através da pena aplicada, afastando a população ainda não criminosa de possível sedução pelo cometimento de um crime; c) prevenção especial positiva, que seria a crença na ressocialização; e d) prevenção especial negativa, que seria a função de inocuização/ incapacitação, de neutralização do ofensor. Nesse artigo defendemos que há um abandono das três primeiras prevenções, 0 cárcere (tradicional) não faz com que as pessoas acreditem ainda mais no Direito, não diminui a criminalidade (conforme já apontamos há pouco com os dados do DEPEN) e não se espera mais a ressocialização, pois como também já mencionamos, há um Estado Inconstitucional de Coisa sobre o sistema penitenciário. Mas ainda há sim uma expectativa que as pessoas sejam neutralizadas, retiradas de circulação e 'depositadas' nos estabelecimentos penais.
} 
empírica e epistemologicamente em centros socioeconômicos diversos no nosso (entre alguns deles: ESPING-ANDERSEN, 2002; PALIER, 2010; ESTANQUE, 2017; MORENO, 2012); b) a América Latina apresenta características diversas de outros países igualmente "periféricos": “En América Latina el bienestar ha sido recurrentemente interpelado por su ausencia o su insuficiência" (FRANZONI, 2007), ou seja, aqui o desenvolvimento, os momentos e a transições do bem-estar apresentam contornos próprios, que fazem com que as idades/fases tipicamente europeias do bem-estar social (MORENO, 2012) acabem não tendo igual desenvolvimento, não sendo semelhantes as datas de "nascimento", "fase de ouro" e "decadência" no mundo todo (isso acontece dentro da própria Europa, sendo Portugal um dos últimos países a implementar o Estado de Bem-estar Social, cf. ESTANQUE, 2017); c) Dentro do bloco latino-americano há subdivisões por semelhanças de modelos (FRANZONI, 2007) e, em nossa interpretação, dentro desses blocos, cada realidade estatal faz do país uma miríade de pontos de análise, que tornam a pesquisa fundamental, pois, ainda que seja possível analisar sob o prisma de teorias externas, a bagagem empírica pode trazer considerações únicas, aplicáveis somente em nível nacional.

Uma tentativa de alocação do Brasil precisa necessariamente levar em consideração algumas coisas: a primeira é que a lógica de "conquista" de direitos proposta por Marshall (1967) não teve a mesma ordem no Brasil (CARVALHO, 2011). Já no fim da década de trinta do século $\mathrm{XX}$, aparentemente tínhamos direitos sociais maduros e legalmente previstos, porém não foram conquistados pelo povo, mas sim entregues de cima para baixo pelo governo Vargas.

A segunda é que o Brasil apresenta pelo menos três períodos de bem-estar, conforme Kerstenetzky (2012), sendo o primeiro, que vai de 1930 a 1964, marcado como "bem-estar corporativo", já que se fundava em caixas de assistência social; o segundo, que pertence ao regime ditatorial, apresenta um "universalismo baixo", ampliando timidamente a proteção, porém ampliando a desigualdade social e o terceiro, já no período pós-Constituição de 1988, compreendido como "universalismo estendido", ou seja, uma tentativa de ampliação de proteção social. Fundamental nesse cenário é o papel do neoliberalismo e da globalização do mercado que ele carreou pois, ao mesmo tempo em que o Brasil inseria em sua Constituição uma série de garantias sociais, ele não iria conseguir implementá-las por conta das forças econômicas externas, maiores e com mais força de determinação nos mercados internos.

Este pano de fundo permite trazer a discussão mais geral das políticas públicas voltadas à área social ao debate stricto das políticas criminais, local em que o Brasil, novamente, pode beber de referenciais internacionais, mas precisa de análises empíricas próprias, por apresentar características únicas, demandando assim, teorias forjadas a partir da nossa realidade.

Ao cenário carcerário, a ditadura tem um efeito extremamente significativo, diferentemente do que aconteceu no Estado de Bem-estar Social mais amplo, que experimentou algum crescimento, ainda que singelo, nas políticas criminais somente restou os efeitos da ampliação da desigualdade do período, pois o locus temporal ditatorial não permitiu que acontecesse no Brasil a "contaminação" dos sistemas penitenciários pelo ideal de bem-estar, coisa que aconteceu na Europa e até mesmo nos Estados Unidos:

O Estado deveria ser um agente da reforma assim como da repressão, do cuidado assim como do controle, do bem-estar assim como da punição. A justiça criminal no emergente Estado de bem-estar não era mais - ou pelo menos não era apenas - a relação entre o Leviatã e o súdito rebelde. Em vez disto, a justiça criminal se tornou, em parte, um Estado de bem-estar, ao passo que o indivíduo criminoso, especialmente o jovem, o desfavorecido ou a mulher, passou a 
ser objeto de necessidades assim como da atribuição de culpa, passou a ser um "cliente" tanto quanto um criminoso (GARLAND, 2008, p. 110).

O máximo que se pode colocar como tentativa de um estado de bem-estar penal no Brasil foi no governo Franco Montoro, em São Paulo, na década de 1980, com ideal progressista e amplamente contra a ditadura, quando à frente do governo estadual, criou as "comissões de solidariedade", nelas os presos adquiriam representatividade junto às autoridades estatais, através de porta-voz eleito entre os presos (ALVAREZ; SALLA; DIAS, 2013).

Essa proposta não tardou a ser combatida duramente pois, ainda que o país não tenha experimentado aquilo que Garland (2008, p. 104) chamou de "previdenciarismo penal" e que Wacquant (2011, p. 85) chama de "Estado-providência" (2011, p. 85) da mesma forma como o eixo europeu-norte americano, a face mais obscura do momento pós-previdenciarismo penal foi aplicada com igual ou maior intensidade aqui, revivendo o Leviatã, através da:

[...] construção de um "novo governo da miséria" no qual a prisão ocupa uma posição central e que se traduz por uma severa imposição de tutela e controle minucioso dos grupos marginais na base da pirâmide social americana. Assim, desenha-se a figura de um novo tipo de formação política, espécie de "Estadocentauro", dotado de uma cabeça liberal que aplica a doutrina do "laissez-faire, laissez passer" em relação às causas das desigualdades sociais, e de um corpo autoritário que se revela brutalmente paternalista e punitivo quando se trata de assumir as consequências dessas desigualdades (WACQUANT, 2002, p. 15).

O resultado dessa sociedade altamente desigual, que credita o peso de todos os méritos e fracassos sobre o indivíduo (HAN, 2015), acaba por produzir "una serie de efectos psicológicos y sociales que influyen sobre la política y el diseño de políticas públicas” (GARLAND, 2007, p. 259), o Estado que combatia a pobreza e as mazelas através da redistribuição de renda e na crença da ressocialização, passa a combater a miséria com a ampliação do encarceramento, inaugurando um "Estado-penitência” (WACQUANT, 2011, p. 85).

Esse tipo de visão de mundo acaba por impactar de forma mediata no sistema penitenciário, a exemplo: quando a população se volta contra o investimento feito para se ter presos representados politicamente (comissões de solidariedade) e essa proposta acaba, não tarda o surgimento paralelo de um mecanismo que tente devolver voz ao preso, surgindo assim o Primeiro Comando da Capital (ALVAREZ; SALLA; DIAS, 2013).

Mas isso não significou abolir o sistema, pelo contrário, somente fez uma nova lógica surgir, dando a reabilitação, lugar à incapacitação dos sujeitos. O cárcere deixou de ser algo com finalidade positiva, exercendo agora somente a função de segregar aqueles que não se enquadrassem no novo modelo. Uma vez deslocado completamente para a face negativa das estruturas que compõe o Estado e a sociedade, não demora para os presídios serem sucateados (a exemplo do Brasil) ou privatizados (em locais como Estados Unidos, Inglaterra e Austrália) (WACQUANT, 2015).

Garland (2002, p. 88), mais tarde, vai chamar isso de criminologia do outro: "criminologia do outro, do pária ameaçador, do estrangeiro perturbador, do excluído e do desagradável [...] tende a diabolizar o criminoso, a estimular os medos e as hostilidades populares e a sustentar que o Estado deve punir mais".

Essas descobertas teóricas facilitam o entendimento do porquê o sistema carcerário chegar a esse ponto: ele chegou porque tanto Estado como população, numa relação reflexiva, autorizam 
e querem que o cárcere tenha uma só finalidade, a de incapacitar, pois recuperar é algo que se tornou 'mau investimento'.

É exatamente nessa fratura, entre as necessidades básicas que vão sendo negadas aos presos e os apelos por dignidade da pessoa humana, que as APACs surgem como via diversa, inaugural e completamente com outra mentalidade.

\section{Desenho Metodológico}

Foi eleita a APAC de Pato Branco para fazer a pesquisa. Inicialmente foi tentado contato também com a APAC de Barracão, mas houve recusa do ingresso nesse campo de pesquisa. Assim, após a manifestação de interesse pela APAC Pato Branco, fornecendo números e demais dados cruciais à formação do percurso metodológico, foi desenhada a seguinte pesquisa.

Optamos pela abordagem qualitativa porque é ela que melhor se amolda ao problema de pesquisa e fenômeno investigado, especialmente por ter seu foco principal em compreender as relações do ser humano em seus valores, atitudes, crenças e representações (MINAYO; DESLANDES; SOUZA, 2012).

A pesquisa bibliográfica foi utilizada para dar suporte teórico e a pesquisa exploratória para embasar a parte empírica. É exploratório por que, segundo Bourguignon, Oliveira Junior e Sgarbieiro (2012, p. 197) esse tipo de pesquisa permite ao pesquisador a aproximação da realidade que se pretende conhecer ou ajuda na definição de hipóteses. Partindo do reconhecimento que pouco se sabe sobre o fenômeno em análise, essa profundidade de análise é a que melhor se amolda ao que se pretende nesse trabalho.

No que concerne às técnicas de coleta, foi eleita a entrevista com os recuperandos como forma de investigação de campo. A pauta de entrevista (modalidade), foi fechada, pois antes mesmo de ter acesso físico à APAC e à autorização do campo de pesquisa (pré-requisito para submissão ao comitê de ética em pesquisa), os responsáveis de Pato Branco-PR solicitaram a pauta, informando que após a aprovação, nada mais poderia ser incluído. A seguinte pauta foi encaminhada e aprovada:

Quadro 01 - Pauta/roteiro de entrevista.

\begin{tabular}{|l|l|}
\hline \multicolumn{2}{|c|}{ ROTEIRO DE ENTREVISTA ESTRUTURADA A SER REALIZADA COM OS PARTICIPANTES } \\
\hline Questão 1 & Qual unidade prisional estava cumprindo pena anteriormente? \\
\hline Questão 2 & Quanto tempo ficou implantado naquele estabelecimento prisional? \\
\hline Questão 3 & Como era o tratamento que recebia? \\
\hline Questão 4 & Há quanto tempo está na APAC? \\
\hline Questão 5 & Como é o tratamento atual? \\
\hline Questão 6 & Qual o ponto positivo da APAC? \\
\hline Questão 7 & Qual ponto negativo? \\
\hline Questão 8 & Pra você, quais as principais diferenças entre o modelo anterior e o atual? \\
\hline Questão 9 & Como era a vigilância dos agentes penitenciários no sistema antigo? \\
\hline Questão 10 & Como é a vigilância no sistema novo? \\
\hline Questão 11 & $\begin{array}{l}\text { O que faz com que você não cometa nenhum ilícito aqui dentro, a vigilância ou o } \\
\text { tratamento mais digno? }\end{array}$ \\
\hline
\end{tabular}

Fonte: Dados da pesquisa. 
Segundo Gil (2008, p. 113) é exatamente essa finalidade da entrevista estruturada, não permitir que novas perguntas sejam feitas. Ainda que Gil aponte que isso é útil para fins de pesquisa quantitativa, aqui não buscamos essa finalidade, tão somente cumprir um requisito do campo.

O universo dos participantes, inicialmente, eram de 05 (cinco) entrevistados, decidido após contato telefônico com o campo, mas, quando da ida até o campo, por indicação da responsável pela APAC, foram entrevistados todos os 20 (vinte) recuperandos que lá se encontravam, para não gerar, segundo a responsável, diferenciação entre eles, o que poderia ser prejudicial. Isso acabou por tornar a análise mais trabalhosa, porém com maior riqueza de dados. No quadro 02 estão inseridos todos os participantes, com nomes fictícios ${ }^{10}$ e também o sistema de origem (tradicional) e o tempo de inserção no modelo APAC. Estes dados são cruciais à análise da distinção entre os modelos/sistemas:

Quadro 02 - Lista de entrevistados com nomes fictícios.

\begin{tabular}{|c|c|c|}
\hline RECUPERANDO & SISTEMA DE ORIGEM & TEMPO NA APAC \\
\hline Gelson & 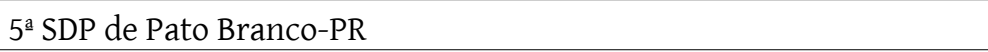 & 7 meses \\
\hline Rildo & Penitenciária Estadual de Francisco Beltrão-PR - PFB & 2 anos \\
\hline Tony & $5^{\text {a }}$ SDP de Pato Branco-PR & 7 meses \\
\hline Fonseca & Penitenciária Estadual de Francisco Beltrão-PR (PFB) & 1 ano e 3 meses \\
\hline Rubens & $5^{\mathrm{a}} \mathrm{SDP}$ de Pato Branco-PR & 7 meses \\
\hline Leopoldo & Penitenciária Estadual de Francisco Beltrão-PR (PFB) & 10 meses \\
\hline Neves & 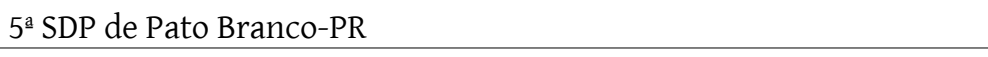 & 7 meses \\
\hline Camões & Penitenciária Industrial de Cascavel-PR (PIC) & 10 meses \\
\hline Braga & Penitenciária Estadual de Francisco Beltrão-PR (PFB) & 10 meses \\
\hline Afrânio & Cadeia Pública de Palmas-PR & 6 meses \\
\hline Tobias & Penitenciária Estadual de Francisco Beltrão-PR (PFB) & 6 meses \\
\hline Leminski & $5^{\mathrm{a}} \mathrm{SDP}$ de Pato Branco-PR & \\
\hline Edgar & Penitenciária Estadual de Francisco Beltrão-PR (PFB) & 11 meses \\
\hline Allan & Penitenciária Estadual de Francisco Beltrão-PR (PFB) & 2 anos e 4 meses \\
\hline Jiano & Penitenciária Estadual de Francisco Beltrão-PR (PFB) & 2 meses \\
\hline Mendel & Penitenciária Estadual de Francisco Beltrão-PR (PFB) & 5 meses \\
\hline Falcão & $5^{\mathrm{a}}$ SDP de Pato Branco-PR & 7 meses \\
\hline Mark & Vários Locais - última 5ª SDP de Pato Branco-PR & 1 ano e 4 meses \\
\hline Geraldo & $5^{\mathrm{a}}$ SDP de Pato Branco-PR e PIC & 7 meses \\
\hline Amadeu & Vários Locais - Penitenciária Estadual de Francisco Beltrão-PR (PFB) & 1 ano e 8 meses \\
\hline
\end{tabular}

Fonte: Dados da Pesquisa.

Afirmamos que a análise exigiu maior labor por conta do método que havíamos eleito no projeto: análise de conteúdo, embasada em Laurence Bardin (2016).

Foram cinco etapas principais seguidas. A primeira delas foi a transcrição de todo o material, visto que as entrevistas puderam ser gravadas. Com a transcrição em mãos, fizemos a leitura flutuante do material, para conhecê-lo melhor e recordar o que tinha sido coletado. Na segunda etapa, chamada codificação, fomos marcando o material com diversas cores, uma cor para cada código que guardasse semelhança com outra palavra em sentido (sinônimo) ou em contexto

\footnotetext{
${ }^{10}$ Os nomes inseridos nesse trabalho são fictícios e não guardam qualquer correspondência ou similitude com os nomes verdadeiros dos recuperandos que estavam na APAC à época das entrevistas.
} 
(sinônimo de contexto), chegamos aos seguintes códigos ${ }^{11}$ : fome, lavagem, comida, moela, limpeza, higiene, custo, tratamento, dignidade. Com a terceira etapa nós criamos a categorização, ou seja, a categoria a ser analisada, que é: o tratamento humanitário recebido na APAC. Dela nós chegamos à quinta etapa (interpretação) através da quarta (inferência). Inferimos nos dados o contexto observado na APAC de Pato Branco, desde a estrutura até os sujeitos, dando especial atenção a quem transmitia a mensagem, qual mensagem transmitia e para qual destinatário. A última etapa foi a interpretação, quando cruzamos as entrevistas com a teoria, fazendo o encontro entre metodologia e epistemologia.

\section{Resultados e Discussões do Tratamento Humanitário recebido na APAC ${ }^{12}$}

Quando o assunto é tratamento humanizado no sistema prisional tradicional, fica difícil (tangenciando o impossível) qualquer mirada com credibilidade para as ações e políticas implementadas, visto que somente se tem notícia de tratamentos cruéis, lotação acima do normal, falta de apoio médico, má alimentação, etc. (MARIZ, 2017).

Essas irregularidades noticiadas não fazem parte de um folclore prisional, não é fruto de uma representação social deslocada da realidade. Afirmamos isso porque dos 20 (vinte) entrevistados, 16 (dezesseis) recuperandos relataram algum tipo/nível de maus tratos vivenciados quando da estadia no sistema tradicional de execução penal.

Em relação à alimentação Amadeu relata o que viveu ${ }^{13}$ :

[...] é obrigado a comer uma comida que era uma lavagem, as vezes muito salgada, as vezes azedas, já peguei carnes que chegava ser azul, não tinha condição de comer, cheguei aqui impossibilitado de tão magro, cheguei aqui pesando 70 e poucos quilos, sendo que eu tenho 1,80 né $[. . .]^{14}$

Ainda em relação à alimentação, Braga descreve a que ponto chega o tratamento desumano e o que isso obriga o ser humano a se sujeitar para não morrer de fome:

[...] é uma cadeia [APAC], mas não é igual lá, é mais sofrido né passa muita fome né, eu vi gente lá comendo papel higiênico. Eu nunca fiz isso, falava pro pessoal usar a mente né, distrair a mente. Faça com que o teu corpo entenda que você não tá com fome, você consegue enganar né, mas tinha uns piazão, com 19 e 20 anos que não aguento e comia papel higiênico, a comida não é que é pouca, a comida é ruim, ela não tem sal, vem carne

\footnotetext{
${ }^{11}$ Como a pesquisa é maior, inserimos somente os códigos que nos levaram a criação da categoria de análise em uso nesse texto.

${ }^{12}$ A construção desse tópico foge um pouco aos demais artigos científicos que optam pela análise de conteúdo como metodologia de análise. O que diverge aqui é o ponto da interpretação. Na maioria das publicações os dados do campo vão sendo intercalados com os referenciais, porém aqui não foi construído dessa maneira. No presente artigo, são primeiro trazidas as falas dos participantes, para depois realizar a análise com os referenciais. Isso foi optado por conta da natureza exploratória desse estudo e também pela escassez de resultados para a temática APAC. Para que se tenha conhecimento, em buscas realizadas junto ao sistema CAPES, no Portal de Periódicos, há somente 06 resultados para a busca combinada APAC + CONDENADO. Destes 6, somente 4 versam de fato sobre APACs e em nenhuma delas há contato direto com os recuperandos na pesquisa de campo, logo, a opção por trabalhar mais com as falas e menos com a teoria nos pareceu apropriada.

${ }^{13}$ Todas as vezes que usarmos uma transcrição das entrevistas, indicaremos com itálico. O uso desse destaque, ainda que indicado para terminologia estrangeira, visa garantir uma distinção entre as citações diretas e as transcrições, facilitando assim a leitura do trabalho. Também mantivemos algumas figuras de linguagem e alguns erros em relação ao português formal, a fim de não retirar a veracidade da experiência, passível de ser sentida através da leitura.
}

${ }^{14}$ Em resposta à questão 3. 
estragada, sabe aquelas moela de galinha, ela vem com aquela parte com aquela quirera junto, só por Deus, o coração de boi, eu adoro coração de boi, que isso é primeira coisa que a gente assava ali e já era para degustar um pouco [quando estava fora do sistema], quando você abria [a marmita, dentro do sistema] aquele cheiro assim, na marmita, meu Deus [...]. ${ }^{15}$

Na mesma linha, Allan menciona:

[...] A comida era horrivel, ixi, as vezes vinha arroz cru, as vezes vinha azedo, as vezes vinha feijão cru tipo fervido, sabe? Aferventadão, as vezes vinha aquelas moelas de galinha sem tirar aquela pelezinha que tem dentro assim, tinha que comer né, tinha que, como nos falava, umas remadas [empurrar a comida como quem rema um barco] né [...] ${ }^{16}$

Na APAC essa realidade é diferente, a comida ainda é custeada pelo Estado, como utensílio básico para a manutenção do ser humano, por meio de convênio; os demais gastos são custeados por meio de doações, ainda, os alimentos são preparados pelos recuperandos, evitando desperdícios e aumentando a qualidade (FBAC, 2017).

Conforme Menezes (2014) descreve o que relatou Dias, socióloga e pesquisadora do Núcleo de Estudos da Violência da USP sobre a comida, "Quando preparada pelos presos, a qualidade da comida é muito superior àquela da terceirizada e custa menos".

Nesta linha, Fonseca, um dos recuperandos que tem a função de cozinheiro na APAC, contou: "[...] eu mesmo que fiz a comida né, então a gente come a comida feita todo dia, nós mesmo que fazemos a comida, é uma comida saudável né, bem temperadinha, uma comida simples, mas bem temperadinha [...]". ${ }^{17}$

Falcão, também cozinheiro, menciona como é a preparação dos alimentos:

[...] come na hora certa, alimentação não é ruim, tem uns dias que falta alguma coisinha, mas a gente quando tá na cozinha, faltou um alho, faltou uma cebola, nós gostamos de comida temperada sabe, mas Deus o livre, aqui dentro a comida é mais regrado um pouquinho né, e nós somos mais exagerado em carne, churrasco essas coisas assim [fora da unidade], mas digamos assim, tirando um pouco isso ai, é muito bom, se vê que quem prepara é a gente mesmo, cuidar a maior limpeza que puder né, na higiene, lavar tudo bem organizadinho, arrumadinho [...].18

Tobias ainda complementa "[...] almoçar na mesa, você almoça com uma faca e com um garfo, com colher [...].$^{19}$ Pode parecer simples, mas o que os presos observam mais e que mais valorizam no sistema APAC não é exatamente o luxo, mas o respeito ao mínimo existencial, como higiene na hora da alimentação, comida suficiente.

Concedendo um sistema muito mais humanizado e entregando minimamente o mínimo, o custo médio por preso nas APACs não passa de um salário-mínimo por mês (RIBEIRO, 2014).

Os recuperandos sabem que o divulgado com gastos por presos na mídia é alto e que isso também influencia na forma como as pessoas olham para o cárcere, conforme Edgar:

\footnotetext{
${ }^{15} \mathrm{Em}$ resposta à questão 5.

${ }^{16} \mathrm{Em}$ resposta à questão 3.

${ }^{17} \mathrm{Em}$ resposta à questão 6.

${ }^{18} \mathrm{Em}$ resposta à questão 6.

${ }^{19} \mathrm{Em}$ resposta à questão 6.
} 
[...] Porque aqui tem até a diferença do que o governo paga pra nós, pode pergunta ali na frente ali, na cadeia, pergunte quanto vale um preso que tá, porque a população se enraiva tanto de nós, tem ódio de nós, porque cada preso lá é $R \$ 1.000,00$ por mês, o outro é $R \$ 2.000,00$ as vezes, e não gasta nem isso, o que vai de kit pra nos lá, pra mim, te falo a verdade, um $\mathrm{G} 2$ desse amarelinho, ainda nem da Bic era, bem fraquinho, escova de dente dessas de $R \$ 0,20, R \$ 0,30$ centavos, uma escovinha pra da pro mês, só um 01 rolo de papel higiênico por mês, e daí? [...]. ${ }^{20}$

Leopoldo também menciona os gastos:

[...] se for ver para muitos ficou manda essa parte tal para eles é um adianto, porque todo mês vai cair à verba daquele preso, no sistema comum um preso vai custar $R \$ 2000$ mil e pouco, e acho que aqui não chega a $R \$ 800, R \$ 900$ reais por mês né, Então veja bem para eles é lucro, agora a forma de tratamento é difícil [...]. ${ }^{21}$

Além da alimentação há outras irregularidades no sistema comum, como as agressões físicas e superlotação. Alguns recuperandos, como Jiano, relataram “[...] Meio bruto na verdade, conforme ia chegando. No começo nos que inauguramos o CDR [Centro de Detenção e Ressocialização], cheguemos os primeiros presos, cheguemos lá e fomos espancados, e mão pra trás, cabeça pra baixo e licença até para os portão [...]".22

Nesta esteira, Rildo:

[...] Lá é sim senhor e não senhor, senão, como diz "o pau no gato e tapa na orelha", chute na bunda, "baixa cabeça vagabundo", preconceito é grande. Os agentes ou a polícia quando da geral, daí nós tem que sair, de coruja que a gente fala, que é só de cueca, sai meio nu, eles só chegam e batem, agora é só tranca, as trancas tudo por cabo, abre as trancas e falam, geral geral, tudo mundo só de coruja, vai pro pátio, tem que ser rápido, pode tá dormindo [...]. ${ }^{23}$

Edgar:

[...] Lá é complicado né, complicado pelo modo que assim, tá muito tumultuado, tipo a higiene lá é muito né, não tinha higiene lá na verdade né, não tinha sossego digamos assim né, um tumulto assim na forma de vozeredo coisarada assim, porque o espaço era pequeno daí era direto aquela tumultuação na verdade [...]. ${ }^{24}$

Gilmar:

[...] Olha pra falar a verdade todo mundo conhece o que é o tratamento de um preso, eles tratam a maneira dos presos parelho, a mesma brutalidade, mesmo gesto de tratar, aquele tipo que tem que sofre, tem que passar falta das coisas, é desse tipo [...]. ${ }^{25}$

\footnotetext{
${ }^{20} \mathrm{Em}$ resposta à questão 3.

${ }^{21} \mathrm{Em}$ resposta à questão 8.

${ }^{22} \mathrm{Em}$ resposta à questão 3.

${ }^{23} \mathrm{Em}$ resposta à questão 3.

${ }^{24} \mathrm{Em}$ resposta à questão 3.

${ }^{25} \mathrm{Em}$ resposta à questão 3.
} 
E assim vai se repetindo os relatos da falta de dignidade no sistema, sendo na APAC o oposto, como Amadeu relatou [...] nossa, totalmente diferente né, meu delito fica lá fora né, quem entra aqui é um homem né, uma pessoa, a direção me tratam super bem, tudo que eu preciso eles tentam me ajudar [...]. ${ }^{26}$

O mesmo Amadeu é certeiro em sua fala: “[...] lá é tratado bem mal, lá [no sistema tradicional] eles não tratam a gente como ser humano [...]" (grifo nosso). ${ }^{27}$

Em contrapartida, o carinho aparece nas falas como algo que marca os recuperando. Allan conta:

[...] Aqui é 100\% né. Uma coisa que me marco muito quando eu cheguei aqui foi, nas penitenciárias chega com xingamento quando você chega, e aqui fui recebido com um abraço [...] 0 respeito, aqui não tem xingamento, se tá fazendo que tá fora do método eles chamam pra conversar cara, eles não chegam com 4 pedras na mão te tacando, te da uma falta por causa disso, não, te chamam e te explicam te aconselham não faça mais, não é assim, ai se tornar daí a agente sabe, foi aconselhado, ai é por né [...]. (grifo nosso) $)^{28}$

Tobias também menciona o abraço, quando chegou na APAC “[...] Fui recebido com abraço né, eu não tenho queixa nenhuma daqui [...]". ${ }^{29}$

Edgar enfatiza a dignidade:

[...] Aqui já muda né, já muda da água pro vinho né, pode ver que é sereno as coisas ai né, tem um espaço adequando para a quantidade de recuperando aqui né, um espaço ótimo na verdade assim, para você refletir né, na verdade passa o tempo todo refletindo né, por que se vê a situação que a gente ta cumprindo uma pena dignamente aqui né, dai aonde a gente veio, então né, a gente nota a diferença todos os dias, não tem nem comparação na verdade né [...]. (grifo nosso) ${ }^{30}$

Ao decorrer da pesquisa, verificou-se que na APAC a dignidade do ser humano é colocada em primeiro plano na busca da ressocialização dos recuperandos que ali estão, sendo que estes sentem esta diferença de tratamento logo que chegam, como descreveu Geraldo na sua chegada:

[...] porque eles acolheram muito bem quando nós chegamos do portão lá fora pra dentro, eles disseram não, o senhor faz o favor tirem as algemas deles aqui não entram algemados, então desceram a escadaria chorando, abraçaram nos, 'sejam bem vindos' $[\ldots . .]^{31}$

Estes relatos vão se repetindo nas demais falas, como algo que marcou, visto que alguns não sabiam o que era receber um carinho. Sendo um dos principais influenciadores da sua ressocialização.

Essas falas permitem apontar, não somente os méritos do sistema APAC, mas, principalmente, os deméritos do sistema tradicional. As falas dos participantes vão exatamente no mesmo

\footnotetext{
${ }^{26} \mathrm{Em}$ resposta à questão 5.

${ }^{27} \mathrm{Em}$ resposta à questão 3.

${ }^{28}$ Em resposta à questão 5.

${ }^{29}$ Em resposta à questão 5.

${ }^{30} \mathrm{Em}$ resposta à questão 5.

${ }^{31}$ Em resposta à questão 5.
} 
sentido que Garland (2002, 2008) e Wacquant (2002, 2011, 2015), e que os outros muitos outros criminólogos, assistentes sociais, sociólogos e toda gama de cientistas sociais que estudam o cárcere apontam, que a crença no ser humano deu lugar ao ódio e que o preso não passa de um péssimo investimento, por isso o sucateamento dos estabelecimentos penais é uma presença constante, porque não se investe naquilo que é impopular.

Lembrando das finalidades da pena, o que a APAC parece querer resgatar são as prevenções perdidas, principalmente a especial positiva, tanto pela forma como trata o recuperando, como pela aproximação da sociedade com o cárcere. A APAC não visa extinguir o modelo de punição através da pena, mas tenta fazer com que o cárcere não seja somente um local de sofrimento, em que as pessoas precisem experienciar o Direito em sua forma mais inumana.

\section{Considerações Finais}

Logicamente nós reconhecemos que toda pesquisa social é localizada e datada, talvez os resultados obtidos na investigação da APAC de Pato Branco-PR não sejam replicáveis em outros contextos sociais e em outros momentos históricos. Porém, considerando o número cada vez maior de APACs e também a estabilidade das informações que circulam sobre elas, nos parece que os malefícios do sistema APAC já estariam evidenciados em pesquisas científicas, especialmente porque tudo aquilo que não funciona no sistema carcerário, salvo o seu próprio não funcionamento, não tarda a ter os holofotes apontados para liquidar qualquer tentativa de melhoria da vida 'dos outros'.

A APAC de Pato Branco aparece num horizonte que parecia perdido pelo excesso de invisibilização. Ela reabre as portas da humanização do cárcere e demonstra ter influência direta na percepção do próprio recuperando sobre as finalidades da privação de liberdade.

Por uma perspectiva teórico-prática, podemos afirmar que a APAC, através do exercício da alteridade, resgata o estado de bem-estar carcerário e confronta a criminologia do outro, desmistificando a versão construída de um preso-monstro.

A estruturação da APAC e os resultados coletados mostram que "gente de bem", sem hipocrisia, aparentemente sem "raiva por dentro", até curiosos, mas de forma alguma interpretando o cárcere como um zoológico, podem ser o caminho para uma reestruturação sistêmica do cárcere e da sua finalidade.

\section{Referências}

AGAMBEN, Giorgio. Homo Sacer: O Poder Soberano e a Vida Nua. 2.ed. Tradução de Henrique Burigo. Belo Horizonte: Editora UFMG, 2002

ALVAREZ, Marcos César; SALLA, Fernando; DIAS, Camila Nunes. Das Comissões de Solidariedade ao Primeiro Comando da Capital em São Paulo. Tempo Social, São Paulo, v. 25, n. 1, p. 61-82, 2013.

BARDIN, Laurence. Análise de conteúdo. São Paulo: Edições 70, 2016.

BOURGUIGNON, Jussara Ayres; OLIVEIRA JUNIOR, Constantino Ribeiro de; SGARBIEIRO, Márcia. Pesquisa Exploratória: concepção e percurso metodológico. In: BOURGUIGNON, Jussara Ayres; OLIVEIRA JUNIOR, Constantino Ribeiro de (orgs.). Pesquisa em Ciências Sociais: interfaces, debates e metodologias. Ponta Grossa: Toda Palavra, 2012. 
CAMPOS, Ricardo. Pai das APACS será indicado ao Prêmio Nobel da Paz. 2017. Disponível em: <http://boasnovasmg.com.br/2017/12/19/pai-das-apacs-sera-indicado-ao-premio-nobel-da-paz/>. Acesso em: 10 jan. 2019.

CARVALHO, José Murilo. Cidadania no Brasil: o longo caminho. 14.ed. Rio de Janeiro: Civilização Brasileira, 2011.

CNJ. Ressocializar presos é mais barato que mantê-los em presídios. 2017. Disponível em: <http:// www.cnj.jus.br/noticias/cnj/84606-apac-onde-ressocializar-preso-custa-menos-que-nos-presidios>. Acesso em: 17 jan. 2019.

D’AGOSTI, Caroline Trevisol; RECKZIEGEL, Roque Soares. O Método APAC é a Humanização do Sistema Penitenciário Brasileiro. Revista síntese, Porto Alegre, Ano XVI, v. 95, p. 9-32, nov./dez. 2016.

DEPEN. Participação Social. 2019. Disponível em: <http://depen.gov.br/DEPEN/acesso-a-informacao/ participacao-social>. Acesso em: 25 jun. 2020.

ELIAS, Norbert; DUNNING, Eric. A busca da excitação. Lisboa: Difel, 1992.

ESPING-ANDERSEN, Gøsta Why we need a new welfare state. Oxford: University Press, 2002.

ESTANQUE, Elisio. Portugal e o Estado Providência. NORUS, v. 5, n. 8, p. 33-70, ago./dez. 2017.

FBAC. APACs filiadas à FBAC no Brasil. 2017. Disponível em: <http://www.fbac.org.br/index.php/pt/ realidade-atual/mapas>. Acesso em: 31 jan. 2019.

FBAC. Quem somos?. 2016. Disponível em: <http://www.fbac.org.br/index.php/pt/institucional/ institucional/>. Acesso em: 03 jan. 2019.

FOUCAULT, Michel. História da Sexualidade: a vontade de saber. 7.ed. Rio de Janeiro: Paz e Terra, 2014.

FRANZONI, Juliana Martínez. Regímenes de bienestar en América Latina: ¿Cuáles y Cómo son? Madrid: Fundación Carolina, 2007.

GARLAND, David. A cultura do controle: crime e ordem social na sociedade contemporânea. Rio de Janeiro: Revan, 2008. (Coleção Pensamento Criminológico nº 16)

GARLAND, David. As Contradições da sociedade punitiva: o caso britânico. In: Discursos sediciosos, n. 11. Rio de Janeiro: Revan, 2002.

GARLAND, David. Crimen y castigo en la modernidad tardía. Bogotá: Siglo del Hombre, 2007.

GIL, Antonio Carlos. Métodos e técnicas de pesquisa social. 6.ed. São Paulo: Atlas, 2008.

GONÇALVES, Hugo Borba; ROCHA, Eliezer Isaac de Oliveira. O desafio de humanizar a execução penal através do método APAC. Percurso, Curitiba, v. 1, n. p. 137-143, 2017.

HAN, Byung-Chul. Sociedade do cansaço. Petrópolis: Vozes, 2015.

KERSTENETZKY, Célia Lessa. 0 Estado do bem-estar social na idade da razão: a reinvenção do Estado Social no mundo contemporâneo. Rio de Janeiro: Elsevier, 2012.

IPEA. Texto para discussão. Brasília: Rio de Janeiro: Ipea, 2015 (O desafio da reintegração social do preso: uma pesquisa em estabelecimentos prisionais) 
MAGALHÃES, Breno Bahia. O Estado de Coisas Inconstitucional na ADPF 347 e a sedução do Direito: o impacto da medida cautelar e a resposta dos poderes políticos. Rev. direito GV, São Paulo, v.15, n..2, p. 1-37, jul. 2019.

MARIZ, Renata, Sistema carcerário brasileiro descumpre a Constituição: irregularidades incluem divisão dos presos por facções e falta de acesso à Justiça. 2017. Disponível em: <https://oglobo.globo. com/brasil/sistema-carcerario-brasileiro-descumpre-constituicao-20744278>. Acesso em: 30 jan. 2019.

MARSHALL, T. H. Cidadania, classe social e status. Rio de Janeiro: Zahar Editores, 1967.

MINAYO, Maria Cecília de Souza; GOMES, Romeu; DESLANDES, Suely Ferreira. Pesquisa social: teoria, método e criatividade. 31.ed. Petrópolis: Vozes, 2012.

MIRANDA, Sirlene Lopes de. A construção de sentidos no método de execução penal APAC. Psicologia \& Sociedade, v. 27, n. 3, p. 660-667, 2015.

MORENO, Luis. La Europa Asocial. Caminamos hacia um individualismo posesivo? Barcelona:

Península, 2012.

MUHLE, Elizana Prodorutti. A prisão terrena no paraíso celestial: APAC, uma alternativa humana ao cumprimento da pena privativa de liberdade. 145f. 2013. Dissertação (Mestrado) - Programa de PósGraduação em Ciências Criminais, Faculdade de Direito, PUCRS, 2013.

OTTOBONI, Mário. Ninguém é irrecuperável: APAC: a revolução do sistema penitenciário. São Paulo: Cidade Nova, 2001.

OTTOBONI, Mário. Vamos Matar o Criminoso?. 3 ed. São Paulo: Paulinas, 2006.

OTTOBONI, Mário; FERREIRA, Valdeci Antonio. Parceiros da ressurreição: jornada de libertação com Cristo e curso intensivo de conhecimento e aperfeiçoamento do Método APAC, especialmente para presos. São Paulo: Paulinas, 2004.

PALIER, Bruno. A Long Goodbye to Bismarck? Amsterdam: Amsterdam University Press, 2010.

PIMENTA, Brenda Estefane; FONSECA, Gema Galgani da. O Método APAC: o resgate da humanização no processo de cumprimento de pena de condenados Rev. Psicol Saúde e Debate, v. 4, n. 2, p. 42-56, jul. 2018.

QUEIROZ, Alvaro. Sobre o conceito de catarse na poética de Aristóteles. Entrelinhas, v. 1, n. 1, 2013. Disponível em: <https://revistas.cesmac.edu.br/index.php/entrelinhas/article/view/214 >. Acesso em: 15 jun. 2020.

RIBEIRO, Diego. Método aumenta reinserção de presos. 2014. Disponível em: <http:// www.gazetadopovo.com.br/vida-e-cidadania/metodo-aumenta-reinsercao-de-presos9fvuivj058d3vx1ab4pkjylam>. Acesso em: 01 fev. 2019.

SÁ, Frankarles Genes De Almeida e. A importância do método de associação e proteção aos condenados (Apac) para o sistema prisional brasileiro. Revista Direito \& Dialogicidade, Ano III, v. III, dez. 2012.

SANT'ANNA, Sebastiao Cesar Meirelles. Reintegração social ou ressocialização: a visão utilitária da educação para jovens e adultos em situação de privação de liberdade. PERSPECTIVA, Erechim. v. 38, n.144, p. 49-62, dez.2014

SILVA, Magno L. Medeiros da. Mimese versus catarse: a questão da violência na TV Comun. inf., Goiânia, v. 1, n. 1, p. 74-94, jan./jun. 1998. 
TJMG. TRIBUNAL DE JUSTIÇA DE MINAS GERAIS. A execução penal à luz do método APAC. Organização de Jane Ribeiro Silva. Belo Horizonte: TJMG, 2011.

TJMG.TRIBUNAL DE JUSTIÇA DE MINAS GERAIS. O Projeto Novos Rumos na Execução Penal Passar a denominar Novos Rumos de Acordo com a Resolução no 633/2010. 2009. Disponível em: <http:// ftp.tjmg.jus.br/presidencia/novos_rumos_/cartilha_apac.pdf>. Acesso em: 31 jan. 2019.

TOZI, Thalita A. Sanção. A (re)interpretação do papel da progressão de regime de cumprimento de pena à luz do pensamento de Alessandro Baratta. Revista Liberdade, São Paulo, ed. 20, p. 85-106, set./dez. 2015

WACQUANT, Loïc. A ascensão do Estado penal nos EUA. In: Discursos Sediciosos, n. 11. Rio de Janeiro: Revan, 2002.

WACQUANT, Loïc. As prisões da miséria. 2.ed. Rio de Janeiro: Zahar, 2011.

WACQUANT, Loïc. Punir os pobres: a nova gestão da miséria nos Estados Unidos: onda punitiva. 3.ed. Rio de Janeiro: Revan, 2015. (Coleção Pensamento Criminológico nº 6).

ZACCONE, Orlando. Indignos de vida: a forma jurídica da política de extermínio de inimigos na cidade do Rio de Janeiro. Rio de Janeiro: Revan, 2015. 